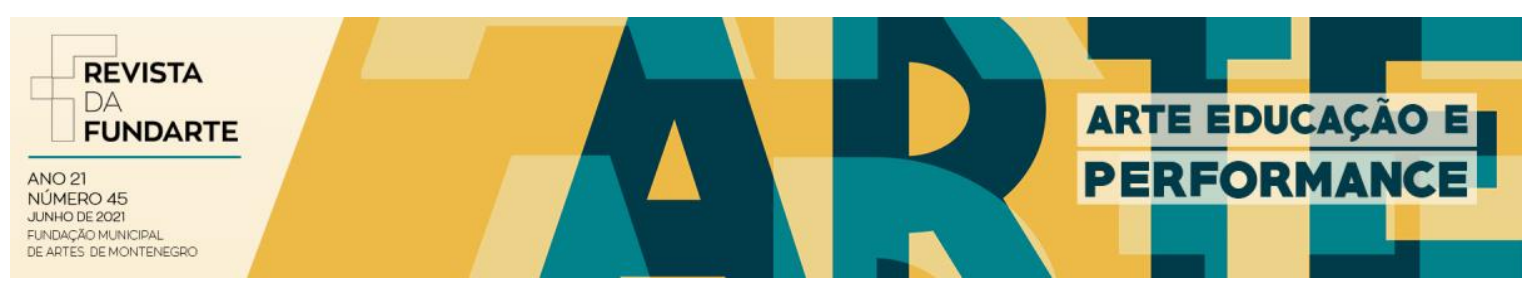

\title{
ANÁLISE DO COMPORTAMENTO VOCAL NO CANTO DO CHAMAMÉ
}

Adrielly Oissa

DOI: $10.19179 / 2319-0868 / 774$ 


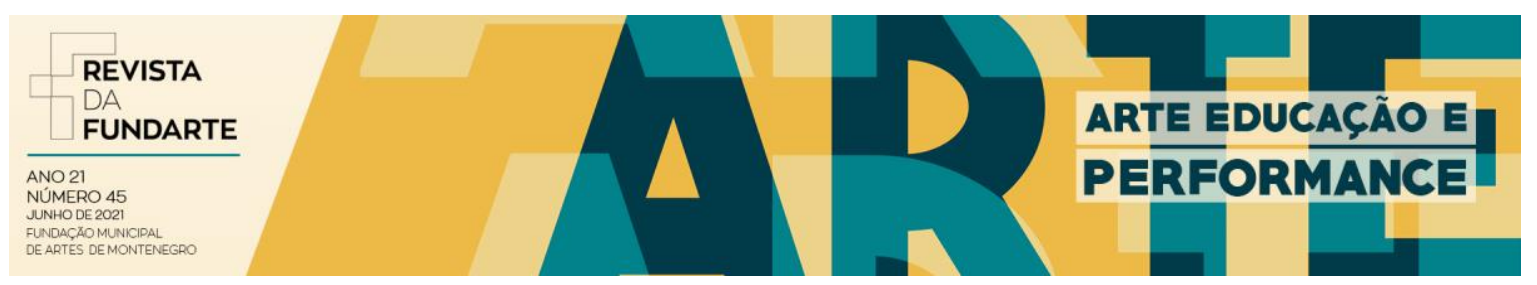

\title{
ANÁLISE DO COMPORTAMENTO VOCAL NO CANTO DO CHAMAMÉ
}

Adrielly Oissa ${ }^{1}$

\begin{abstract}
Resumo: Não existem pesquisas específicas, que se desdobram sobre o aspecto vocal ou interpretativo dos cantores de chamamé. Fundamentando-se nos parâmetros de análise vocal utilizados por Piccolo (2006) e Machado (2012) em seus estudos sobre o canto popular brasileiro e, nos escritos de Tatit (2012) sobre a canção popular, a autora realiza um estudo sobre as características de comportamento vocal no canto do chamamé, gênero musical característico da região comportada pelo noroeste argentino (províncias de Misiones, Corrientes e Entre Rios), sul do Brasil e Paraguai. Além de ampliar o conhecimento sobre esse gênero musical, os resultados desse estudo poderão servir de material de apoio à atividade didática do canto popular na América-Latina.
\end{abstract}

Palavras-Chave: Canto Popular; Técnica Vocal; Comportamento Vocal.

\section{ANALYSIS OF VOCAL BEHAVIOR IN THE CORNER OF CHAMAMÉ}

\begin{abstract}
There is no specific research, which unfolds on the vocal or interpretive aspect of chamamé singers. Based on the parameters of vocal analysis used by Piccolo (2006) and Machado (2012) in their studies on Brazilian popular singing, and in Tatit's (2012) writings on popular song, the author conducts a study on the characteristics of vocal behavior in the chamamé song, a musical genre characteristic of the region in northwestern Argentina (provinces of Misiones, Corrientes and Entre Rios), southern Brazil and Paraguay. In addition to expanding knowledge about this musical genre, the results of this study may serve as support material for the teaching activity of popular singing in Latin America.
\end{abstract}

Keywords: Popular Singing; Vocal Technique; Vocal Behavior.

\section{INTRODUÇÃO}

A indústria fonográfica e a comercialização da música popular urbana, segundo Chernavsky (2015, p.1), "favoreceu a fixação de gêneros e a fixação e consagração de condutas vocais específicas (e adequadas), associadas à interpretação desses gêneros". Em seu trabalho, ela propõe um estudo dos padrões de comportamento vocal dos gêneros tango, samba e guarânia. Segundo seu relato,

\footnotetext{
1 Especialista em "Educação Aplicada à Performance Musical" pelo Centro Universitário do Sul de Minas, Bacharel em "Música - Canto" pela Universidade Federal da Integração Latino-Americana e, Mestranda em "Estudos Latino-Americanos" pela mesma universidade. Atua como professora de Canto Popular, Pedagogia Vocal, Canto Coral e Técnica e Interpretação Vocal.
}

OISSA, Adrielly. Análise do comportamento vocal no canto do chamamé. Revista da FUNDARTE. Montenegro, p.01-15, ano 21, no 45, junho de 2021.

Disponível em: http://.seer.fundarte.rs.gov.br/index.php/revistadafundarte/index> 30 de junho de 2021. 


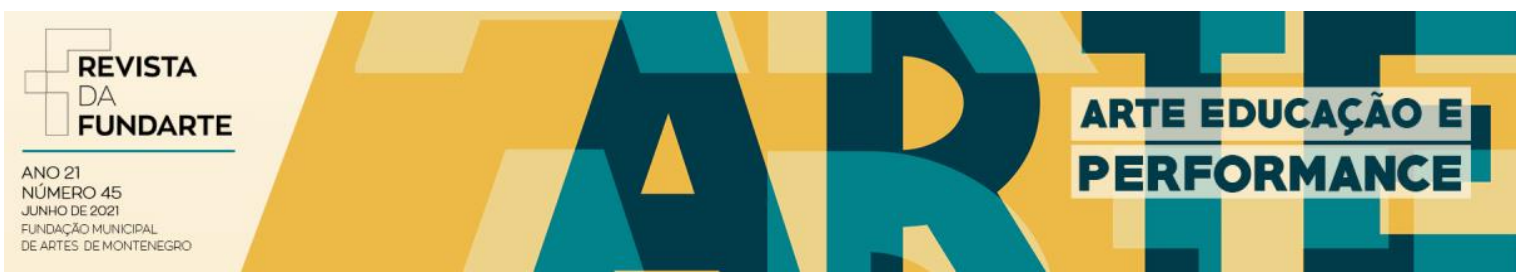

um dos aspectos mais importantes "foi o papel cumprido por ambos os gêneros na construção das identidades nacionais de seus respectivos países" (CHERNAVSKY, 2015, p.2).

Existe uma disputa, pela origem do gênero chamamé, entre os músicos argentinos e paraguaios, porém, a idéia mais forte, é de que seria um ritmo derivado da polca paraguaia, diferindo apenas em sua característica expressiva. De acordo com Cerruti (1965), a melodia do chamamé é mais expressiva e, o uso de ornamentações no canto e saltos melódicos de terças e oitavas no acordeom, assim como a existência de um fraseado melódico que retarda artificialmente os tempos e aparentemente desarticula o compasso, enfatizam seu caráter choroso. Higa (2010) relata que o termo chamamé surgiu no ano de 1930, quando o compositor paraguaio Samuel Aguayo gravou uma canção de Diego Novillo Quiroga e Francisco Pracánico, chamada Corrientes poty. Segundo o autor, o diretor da gravadora RCA Victor, "visando aumentar as vendas do disco na região de Corrientes (norte da Argentina), criou o termo chamamé, que em guarani significa coisa feita rapidamente, improvisada" (HIGA, 2010, p.157). Ainda, segundo ele, "a criação do termo chamamé", associada a essa canção, coroou o "processo de transformação da polca paraguaia, iniciado com a introdução do acordeon no norte da Argentina" (HIGA, 2010, p.159).

Higa (2010, p.162) também descreve que a configuração musical básica do chamamé, polca e guarânia, "é a fórmula rítmica construída com a melodia em compasso binário composto sobre uma base de acompanhamento ternário e com frequente utilização de sincopas na linha do canto". O autor propõe uma análise de trinta canções entre polcas paraguaias, guarânias e chamamés, coletadas entre as mais populares executadas em Campo Grande/MS. Para tal análise, ele seleciona "oito polcas paraguaias; oito guarânias; oito chamamés e dez canções brasileiras compostas a partir da influência da polca paraguaia e guarânia", denominadas "rasqueados brasileiros" (HIGA, 2010, p.170). Sua análise aborda padrões melódicos, rítmicos e harmônicos desses gêneros, porém pouco fala sobre os aspectos em torno do comportamento vocal. 


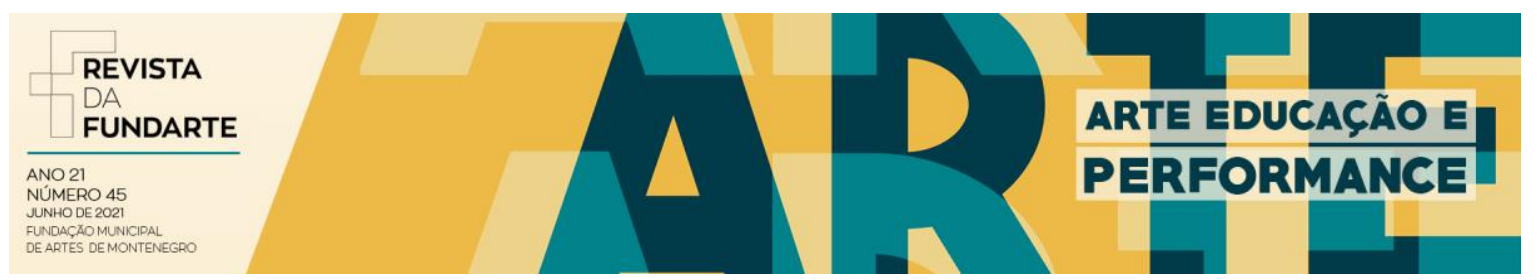

Apesar dos avanços nos estudos referentes à música popular, principalmente a partir da década de 1990, a produção intelectual em torno da performance ou do comportamento vocal, associado à canção popular, ainda continua escassa. Se pensarmos no canto do chamamé, poderíamos dizer que é praticamente inexistente. Segundo Santiago e Nunes (2018, p.1), os livros de canto popular, publicados no Brasil, "dão maior enfoque à técnica para o desenvolvimento de uma sonoridade limpa e equilibrada, bem como ao conhecimento fisiológico do aparelho vocal em detrimento à abordagem sobre interpretação".

O que define o canto como popular, ou não, não é apenas a habilidade técnica aplicada a ele. A isso, soma-se o gesto interpretativo, que é capaz de aproximar a canção, o cantor e o cantar, da cultura, da fala e do cotidiano do intérprete e do ouvinte.

O cantor popular, geralmente, aprende o ofício, ouvindo e imitando outros cantores. Baseado em suas influências musicais, o cantor popular busca definir sua identidade vocal e pessoal através de sua própria interpretação da canção, ao mesmo tempo em que busca transmitir sua identidade nacional e cultural, a fim de que outras pessoas se identifiquem, é isso que faz com que a canção se torne popular, e dá a ela um sentido muito mais amplo. Tatit (2012), ao abordar o tema do cancionista brasileiro, descreve, de forma poética, sobre essa junção da voz que canta com a voz que fala. Segundo ele, a voz que canta é "um corpo imortalizado em sua expressão timbrística", enquanto que "da voz que fala emana o gesto oral mais corriqueiro, mais próximo da imperfeição humana" e, "dessa singular convivência entre o corpo vivo e o corpo imortal brotam o efeito de encanto e o sentido de eficácia da canção popular" (TATIT, 2012, p.16).

No Brasil existem alguns estudos sobre a canção popular que, embora sejam bastante relevantes para a compreensão da canção como linguagem musical, não versam com profundidade o âmbito da performance vocal. Tatit $(2012$, p.9) diz que o cancionista "mais parece um malabarista", pois "tem um controle na atividade que permite equilibrar a melodia no texto e o texto na melodia". Ainda, segundo o autor, "cantar é uma gestualidade oral, ao mesmo tempo contínua, articulada, tensa e natural, que exige um permanente equilíbrio entre os elementos melódicos, 


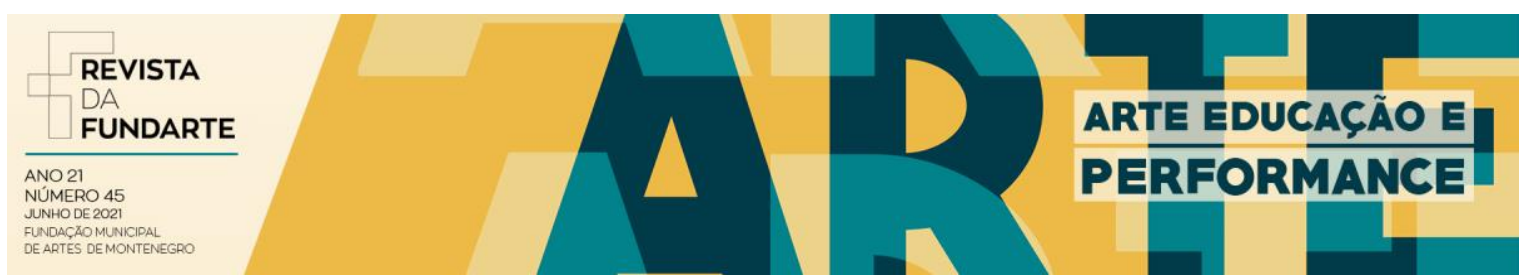

linguísticos, os parâmetros musicais e a entoação coloquial". Piccolo (2005, p.410) diz que não basta que a canção popular "obedeça a determinados padrões melódicos, rítmicos ou harmônicos para que a interpretação esteja de acordo com seu estilo", e Machado (2012, p.53-54) diz que "o gesto interpretativo é a ação que materializa a compreensão do cantor ante os conteúdos da composição", e que desta maneira, "ele torna claro os elos de melodia e letra inscritos na composição, ou mesmo define novos elos que só se consolidam pela presença da voz".

Embora existam alguns estudos a respeito do gênero musical chamamé, esses estudos referem-se, principalmente, à origem histórica do gênero, aos parâmetros musicais, instrumentais, rítmicos, melódicos, e também, a dança. Pouco se fala e, não há pesquisas específicas, que se desdobram sobre o aspecto vocal ou interpretativo dos cantores de chamamé. Piccolo (2006), utilizando parâmetros adotados pelos trabalhos de (ANDRADA E SILVA, 2001; LAVER, 1980; LOMAX,1968), sistematiza recursos interpretativos utilizados no canto popular brasileiro. Após selecionar os parâmetros de análise vocal, ela realiza um minucioso estudo de algumas interpretações de grandes nomes do repertório da música popular brasileira. Machado (2012), também realiza uma análise semiótica do comportamento vocal a fim de evidenciar quais aspectos da voz do cantor seriam responsáveis pela tradução dos sentimentos inscritos na canção. Embora essas pesquisas tenham sido realizadas baseadas nos recursos e padrões vocais utilizados no canto popular brasileiro, as análises realizadas por Piccolo (2006) e Machado (2012) podem servir para embasar, em grande parte, o trabalho de sistematização e análise do comportamento vocal proposto neste estudo².

Portanto, baseando-me nesses parâmetros de análise vocal utilizados por Piccolo (2006) e Machado (2012) em seus estudos sobre o canto popular do Brasil, e ainda, nos escritos de Tatit (2012) sobre o cancionista brasileiro, através de uma bolsa de Iniciação Científica da Universidade Federal da Integração LatinoAmericana (UNILA), ofertada entre os anos de 2018 e 2019, financiada pela Fundação Araucária de Apoio ao Desenvolvimento Científico e Tecnológico do

\footnotetext{
2 Informações retiradas do Projeto de Iniciação Científica da Universidade Federal da Integração Latino-Americana, denominado "Entre tangos, sambas e guarânias: um estudo sobre o comportamento vocal na canção urbana latino-americana"
} 


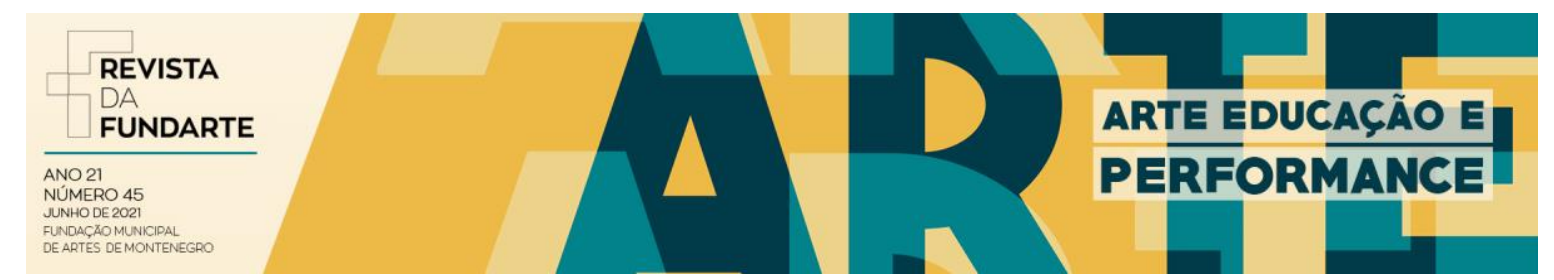

Estado do Paraná (FA) e, com a coordenação e orientação da professora do Curso de Música da UNILA, Dra. Analia Chernavsky, iniciei minhas pesquisas sobre o canto do chamamé que, por fim, me conduziram a materialização deste estudo.

\section{METODOLOGIA}

Para realização deste trabalho, optei por fazer um levantamento de repertório, com base em gravações de canções do gênero chamamé, disponíveis na internet. A idéia inicial seria utilizar um recorte de tempo de quarenta anos, buscando 10 (dez) canções gravadas e/ou regravadas entre 1940 e 1980, que pudessem ser comparadas. Devido à dificuldade em encontrar, disponível na internet, gravações do gênero feitas no início da década de 1940, foram selecionadas apenas 9 (nove) canções e o recorte temporal alcançando com essas canções foi entre 1946 e 1980. As canções analisadas foram as seguintes (nome/compositor):

1. Mercedita - Ramón Sixto Rios;

2. Kilómetro 11 - Mario del Transito Cocomarola e Constante Aguer;

3. Puerto Tirol - Heraclito Peréz e Marcos Ramirez;

4. Lunita de Taraguí - Albérico Mansilla e Edgar Romero Maciel;

5. Posadeña linda - Ramón Ayala;

6. Retrato de un pescador - Ramón Ayala;

7. El boyerito - Tomás Alarcón e Ernesto Dana;

8. Viejo naranjal - Carlos G. Meza e Martin Barrios;

9. Así se baila el chamamé - Mario Milán Medina.

O material coletado foi armazenado e organizado para análise. Os parâmetros utilizados para as análises musicais e, de comportamento vocal de cada uma das interpretações, foram baseados nos parâmetros utilizados por Piccolo (2006) e Machado (2012) em suas propostas de análise do canto popular brasileiro.

A sistematização dos procedimentos técnicos, estilísticos e recursos vocais utilizados foi realizada através da audição e análise deste material. Para sistematizar esses elementos fez-se necessário o uso de três tabelas contendo os dados das 


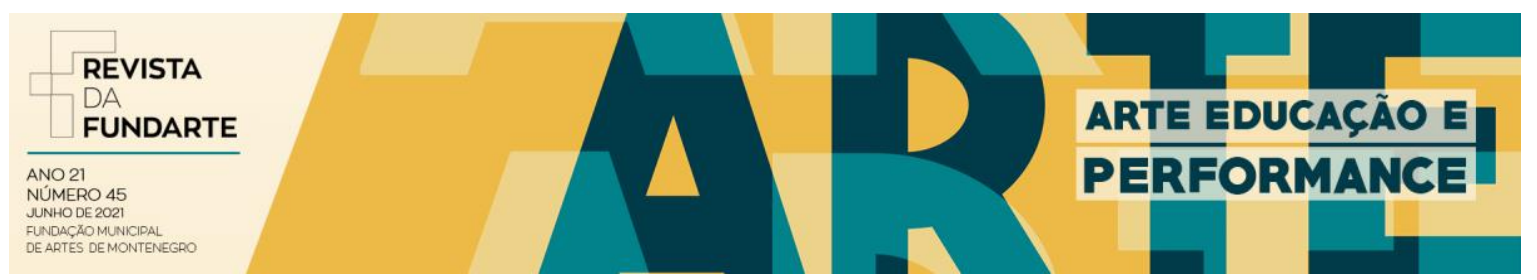

análises, obtidos a partir da escuta das gravações. A seguir, apresenta-se uma síntese do conteúdo das tabelas de análise utilizadas:

- Tabela 1 - DADOS DE IDENTIFICAÇÃO: Título / Compositor/Letrista / Intérprete / Álbum/Série/Faixa / Gravadora / Ano / Repositório digital / Arranjador.

- Tabela 2 - ELEMENTOS PARA ANÁLISE MUSICAL: Tonalidade / Fórmula de compasso / Andamento / Forma / Tessitura da melodia / Instrumentação / Dinâmica / Língua.

- Tabela 3 - ELEMENTOS PARA ANÁlise dA PERFORMANCE VOCAL ELEMENTOS DE APRECIAÇÃO VOCAL: Ataque vocal / Articulação da melodia / Articulação do texto / Brilho / Projeção/Ressonância. POSIÇÃO FISIOLÓGICA DO CANTO: Posição da laringe / Posição dos lábios / Posição da língua / Posição da mandíbula / Registros/Sub-registros. QUALIDADE VOCAL - EFEITOS INTERPRETATIVOS: Voz nasal / Voz rouca / Voz tensa / Voz suja / Voz com ar / Voz falada. QUALIDADE VOCAL - RECURSOS INTERPRETATIVOS: Portamento / Vibrato / Melisma / Trêmulo.

\section{RESULTADOS}

Para cada uma das nove canções, foram analisadas e comparadas duas interpretações diferentes, totalizando assim 54 (cinquenta e quatro) tabelas. Após as análises, os resultados observados foram catalogados e dispostos nas tabelas. A seguir, apresento-os de forma substanciada:

- Tabela 1 - DADOS DE IDENTIFICAÇÃO:

- INTÉRPRETE: 10 (dez) intérpretes com voz masculina e 5 (cinco) intérpretes com voz feminina.

- COMPOSITOR/LETRISTA: todos os compositores são do sexo masculino.

- GRAVADORA: 6 (seis) canções gravadas pela Odeon; 3 (três) pela CBS Columbia; 2 (duas) pela Redondel; 1 (uma) pela Bemol; 1 (uma) pela Diapasón; 1 (uma) pela Califórnia; 1 (uma) pela Asunción; 1 (uma) 


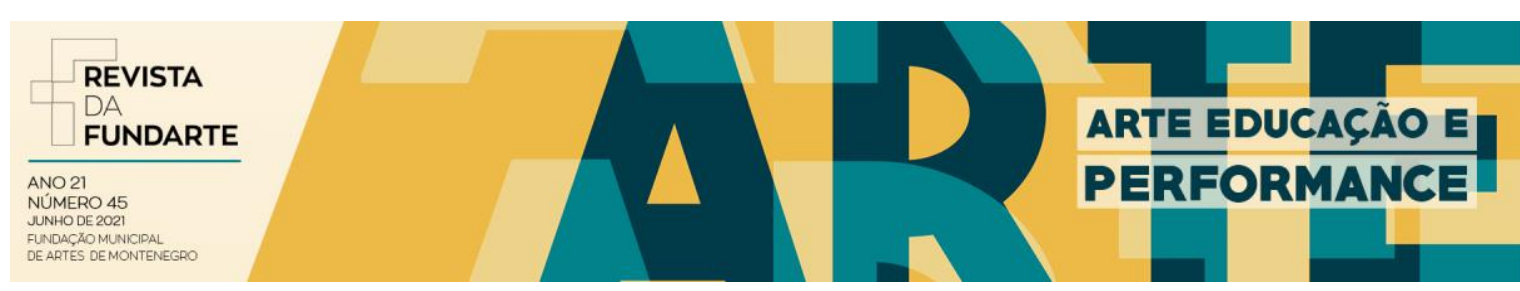

pela Microfon; e em 2 (duas) não encontramos informações a respeito da gravadora.

- ANO: 1 (uma) entre 1946 e 1950; 2 (duas) entre 1950 e 1960; 6 (seis) entre 1960 e 1970; 6 (seis) entre 1970 e 1980; 2 (duas) em 1980; e 1 (uma) não encontramos data precisa de gravação.

- REPOSITÓRIO DIGITAL: das 18 (dezoito) interpretações analisadas, 10 (dez) encontram-se disponíveis no site Fundación Memoria del Chamamé $^{3}$ e, 8 (oito) estão disponíveis na plataforma digital YouTube 4 .

\section{- Tabela 2 - ELEMENTOS PARA ANÁLISE MUSICAL:}

- TONALIDADE: das nove canções analisadas, 4 (quatro) estão em tonalidade menor e 5 (cinco) em tonalidade maior.

- FÓRMULA DE COMPASSO: todas as canções analisadas estão em $6 / 8$.

- ANDAMENTO: o andamento das dezoito interpretações varia entre 110 bpm a 146 bpm.

- FORMA: a forma, de modo geral está dividida em "Introdução-A-Binterlúdio e repetições das seções A e B".

- TESSITURA DA MELODIA: a tessitura das canções abrange em média uma oitava, ultrapassando ou recuando, às vezes, em dois ou três tons.

- INSTRUMENTAÇÃO: 7 (sete) interpretações são acompanhadas de violão (guitarra) e acordeon; 5 (cinco) apenas com violão; 2 (duas) com violão, harpa e acordeon; 1 (uma) com bandoneon e violão; 1 (uma) com violão e contrabaixo; 1 (uma) com orquestra de cordas, contrabaixo e flauta; e 1 (uma) com violão, contrabaixo e acordeon.

- DINÂMICA: 10 (dez) entre mezzo forte e forte; 7 (sete) mezzo forte e, 1 (uma) forte.

3 Site <http://www.fundacionmemoriadelchamame.com/> Acessos realizados entre Janeiro e Abril/2019.

${ }^{4}$ Site <https://www.youtube.com/> Acessos realizados entre Janeiro e Abril/2019. 


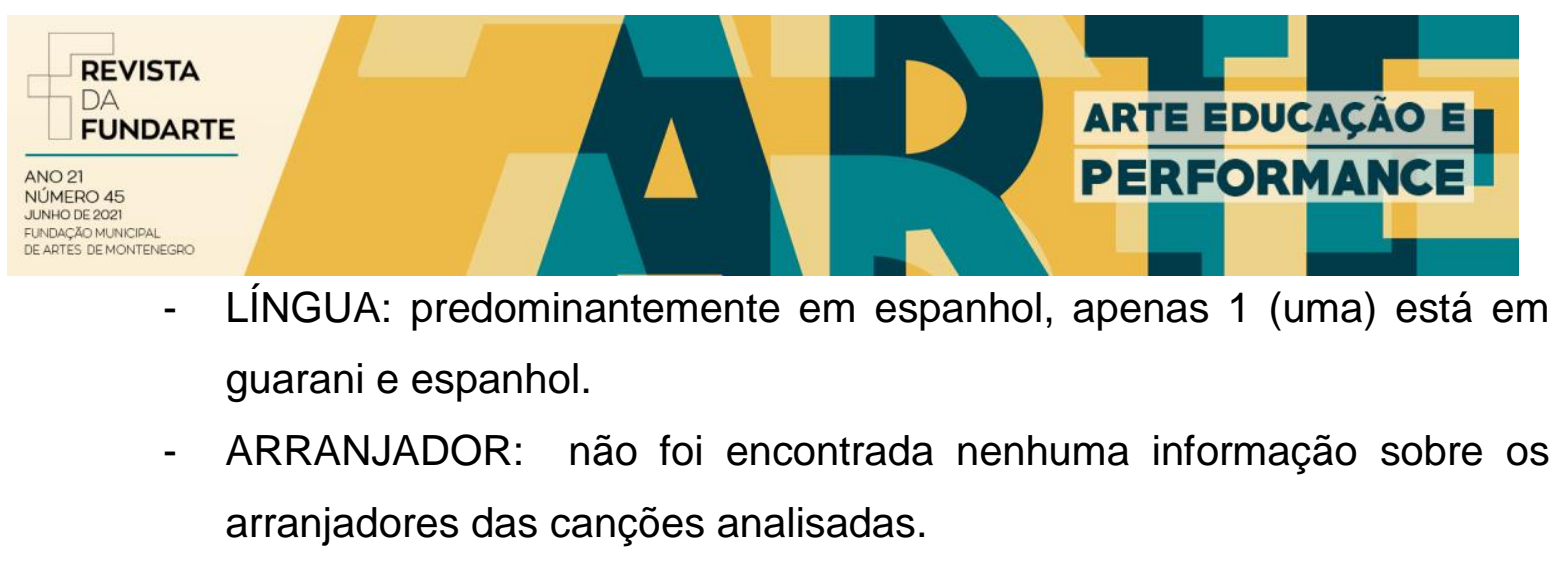

- Tabela 3 - ElEMENTOS PARA ANÁLISE dA PERFORMANCE VOCAL ELEMENTOS DE APRECIAÇÃO VOCAL:

- ATAQUE VOCAL: das interpretações analisadas, 15 (quinze) apresentaram ataque vocal leve e 3 (três) apresentaram ataque vocal médio.

- ARTICULAÇÃO DA MELODIA: 4 (quatro) apresentaram articulação precisa, utilizando legato e staccato e, 14 (quatorze) apresentaram articulação com uso apenas de legato.

- ARTICULAÇÃO DO TEXTO: 8 (oito) apresentaram articulação precisa do texto; 4 (quatro) precisa e aberta; 3 (três) exagerada, precisa e aberta; 1 (uma) imprecisa; 1 (uma) imprecisa e aberta; e 1 (uma) imprecisa e pastosa.

- BRILHO: todas as canções foram interpretadas com bastante brilho na voz.

- PROJEÇÃO/RESSONÂNCIA: 12 (doze) apresentaram projeção e ressonância de forma equilibrada, ou seja, distribuída entre laríngea, oral e nasal; e 6 (seis) laringo-faríngea, onde há predomínio do foco na região do pescoço.

- POSIÇÃO FISIOLÓGICA DO CANTO: com relação à posição fisiológica do canto, é importante ressaltar que nenhuma das gravações encontradas e catalogadas se trata de registro audiovisual, por esse motivo não é possível afirmar com precisão qual é a posição fisiológica. Por tanto, apenas a análise auditiva leva a crer que em todas as canções, os intérpretes, possivelmente, encontravam-se com a laringe em posição neutra ou pouco elevada, o dorso da língua elevado ou pouco elevado, lábios e mandíbula com abertura média e/ou alta. Também foi observado que os intérpretes cantaram em registro modal com sub-registro de peito, com exceção de duas interpretações, de 


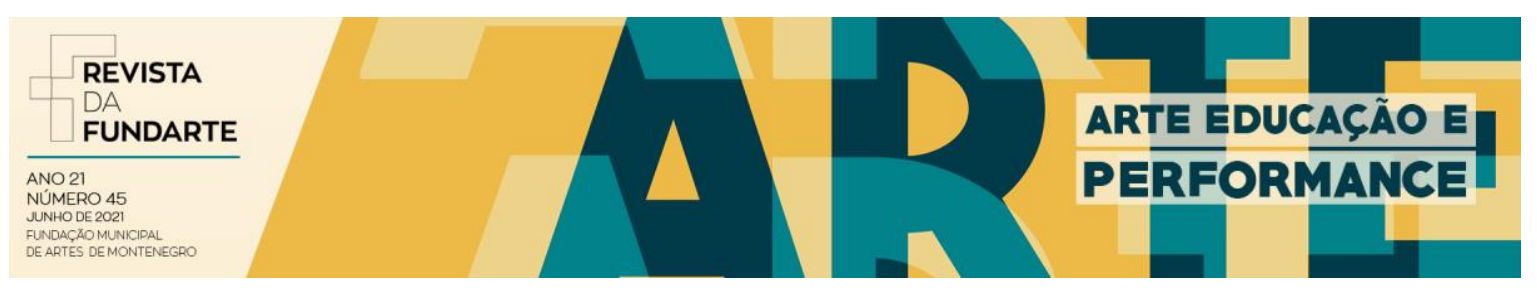

duas canções distintas, na qual observou-se o uso de sub-registro de cabeça também (figuras 1 e 2).

\begin{tabular}{|c|c|c|}
\hline \multicolumn{3}{|c|}{ Tabela 1: Dados de identificação } \\
\hline Título: & El Boy & \\
\hline Compositor/Letrista: & Tomás Alarcón e & nesto Dana \\
\hline Intérprete: & Los Veteranos de Mambrin & Ramona Galarza \\
\hline Ábum/Série/Faixa: & Los Veteranos de Mambrin / faixa 01 "A" & Alma Guarani / faixa 07 " $\mathrm{B}$ " \\
\hline Gravadora: & Bemol & Odeon \\
\hline Ano de gravação: & 1958 & 1962 \\
\hline Repositório digital: & http:/Wwww. fundacionmemoriadelchamame com/discotecg/4/ & https: / ww w youtube com/watch?v=S08vNohJfDg \\
\hline Arranjador: & & \\
\hline
\end{tabular}

\begin{tabular}{|l|c|c|}
\hline \multicolumn{2}{|c|}{ Tabela 2: Elementos para análise musical } \\
\hline Tonalidade: & Ebm & Am \\
\hline Fórmula de compasso: & $6 / 8$ & $6 / 8$ \\
\hline Andamento: & $118 \mathrm{bpm}$ & $118 \mathrm{bpm}$ \\
\hline Forma: & Intro-||:A-B-inter:I-B' & Intro-A-B-Inter-A-B \\
\hline Tessitura da melodia: & Mib2 - Láb3 & Dó3 - Ré4 \\
\hline Instrumentação: & Guitarra e acordeon & Cordas, contrabaixo, flauta \\
\hline Dinâmica: & Mezzo forte & Entre mezzo forte e forte \\
\hline Língua: & Espanhol & Espanhol \\
\hline
\end{tabular}

\begin{tabular}{|l|c|c|}
\hline \multicolumn{3}{|c|}{ Tabela 3: Elementos para análise da performance vocal } \\
\hline \multicolumn{2}{|c|}{ Elementos de apreciação vocal } \\
\hline Ataque vocal: & Leve & Leve \\
\hline Articulação da melodia: & Ligato & Ligato \\
\hline Articulação do texto: & Imprecisa & Sim \\
\hline Brilho: & Sim & Precisa e aberta \\
\hline Projeção / Ressonancia: & Equilibrada (distribuída entre laringea, oral e nasal) & Equilibrada (distribuída entre laringea, oral e nasal) \\
\hline & Posiçäo fisiológica do canto \\
\hline Posição da Laringe: & Neutra & Abertura média e alta \\
\hline Posição dos lábios: & Abertura média & Dorso pouco elevado \\
\hline Posição da língua: & Dorso pouco elevado & Abertura média e alta \\
\hline Posição da mandíbula: & Abertura média & Modal / Peito \\
\hline Registros / Sub-registros: & Modal/Peito e Cabeça &
\end{tabular}

Figura 1

OISSA, Adrielly. Análise do comportamento vocal no canto do chamamé. Revista da FUNDARTE. Montenegro, p.01-15, ano 21, no 45, junho de 2021.

Disponível em: http://.seer.fundarte.rs.gov.br/index.php/revistadafundarte/index> 30 de junho de 2021. 


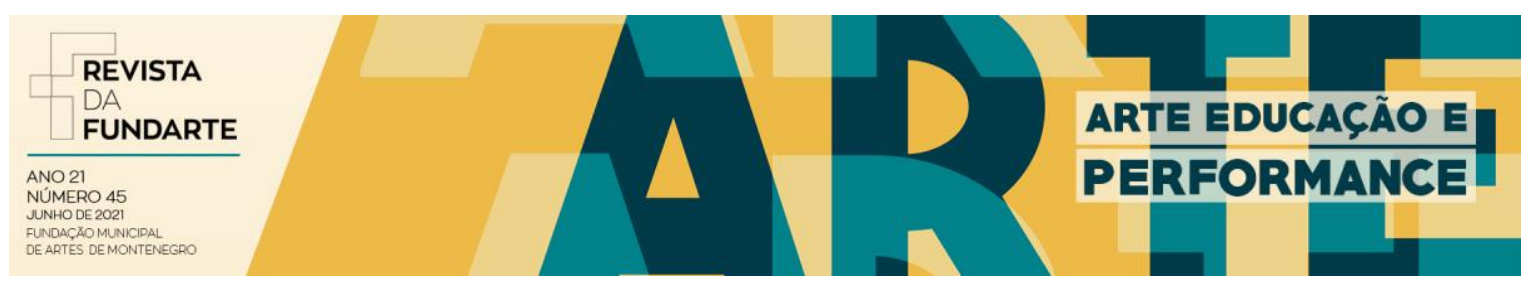

\begin{tabular}{|c|c|c|}
\hline \multicolumn{3}{|c|}{ Tabela 1: Dados de identificação } \\
\hline Titulo: & Viejo Naranjal & \\
\hline Intérprete: & \begin{tabular}{l|l} 
Los Hermanos Barrios &
\end{tabular} & Jandira e Benitez \\
\hline Gravadora: & Asuncion & California \\
\hline Ano de gravação: & 1967 & 1973 \\
\hline Repositório digital: & htto-i/mwwifundacionmemoriadelchamame comidiscoteca/193i\#collapseExampleoeg & htto:// womu fundacionmemoriadelchamame combiografia/709: \\
\hline
\end{tabular}

\begin{tabular}{|l|c|c|}
\hline \multicolumn{2}{|c|}{ Tabela 2: Elementos para análise musical } \\
\hline Tonalidade: & $\mathrm{B}$ & $\mathrm{Bb}$ \\
\hline Fórmula de compasso: & $6 / 8$ & $6 / 8$ \\
\hline Andamento: & $120 \mathrm{bpm}$ & $112 \mathrm{bpm}$ \\
\hline Forma: & Intro-A-B-Inter-A-B & Intro-A-B-Inter-A-B \\
\hline Tessitura da melodia: & $\mathrm{S}$ 2 - Lä\#3 & D b3 - Lá3 \\
\hline Instrumentaçăo: & Guitarra e acordeon & Guitarra, harpa e acordeon \\
\hline Dinâmica: & Entre mezzo forte e forte & Entre mezzo forte e forte \\
\hline Lingua: & Espanhol & Espanhol \\
\hline
\end{tabular}

\begin{tabular}{|c|c|c|}
\hline \multicolumn{3}{|c|}{ Elementos de apreciação vocal } \\
\hline Ataque vocal: & Leve & Leve \\
\hline Articulação da melodia: & Ligado & Ligado \\
\hline Brilho: & $\operatorname{sim}$ & $\operatorname{sim}$ \\
\hline Projeçăo / Ressonancia: & Equilibrada (distribuida entre laringea, oral e nasal) & Equilibrada (distribuida entre laringea, oral e nasal) \\
\hline \multicolumn{3}{|c|}{ Posição fisiológica do canto } \\
\hline Posiçăo dos lábios: & Abertura média & Abertura média \\
\hline Posiçăo da lingua: & Dorso pouco elevado & Dorso pouco elevado \\
\hline Posição da mandibula: & Abertura média & Abertura média \\
\hline Registros / Sub-registros: & Modal / Peito e cabeça & Modal / Peito \\
\hline
\end{tabular}

\section{Figura 2}

- QUALIDADE VOCAL - EFEITOS INTERPRETATIVOS:

- VOZ NASAL: apenas 1 (uma) interpretação apresentou o uso de nasalização.

- VOZ ROUCA: nenhum intérprete utilizou voz rouca.

- VOZ TENSA: 7 (sete) intérpretes utilizaram tensão na voz em algum momento.

- VOZ SUJA/VOZ COM AR: nenhum intérprete apresentou voz suja ou aerada.

- VOZ FALADA: 3 (três) intérpretes utilizaram voz falada na canção interpretada.

- QUALIDADE VOCAL - RECURSOS INTERPRETATIVOS:

- PORTAMENTO: 14 (quatorze) intérpretes utilizaram de portamentos como recursos interpretativos.

OISSA, Adrielly. Análise do comportamento vocal no canto do chamamé. Revista da FUNDARTE. Montenegro, p.01-15, ano 21, no 45, junho de 2021.

Disponível em: http://.seer.fundarte.rs.gov.br/index.php/revistadafundarte/index> 30 de junho de 2021. 


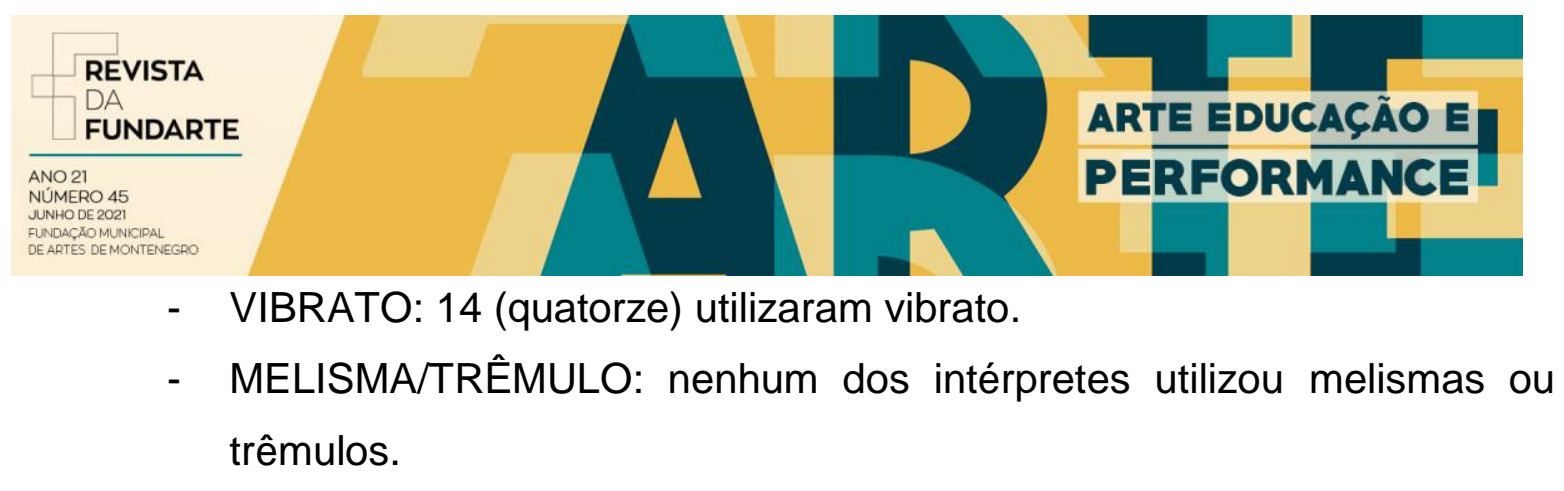

A análise da amostragem revelou que os cantores de chamamé, entre as décadas de 1940 e 1980, utilizavam de recursos vocais que aproximavam a voz cantada da voz falada. Piccolo (2005, p.412) relata um dos recursos responsáveis por essa sensação de aproximação ao descrever que "a predominância do registro de peito poderia explicar a sensação de proximidade com a voz falada".

Além dessa proximidade entre a voz cantada e a voz falada, foi possível observar a presença da fala, propriamente dita, sendo utilizada por três intérpretes. Tal recurso normalmente é utilizado com o intuito de chamar a atenção do ouvinte e ajudar a narrar a história cantada. Nas interpretações da canção Posadeña Linda, de Ramón Ayala, os dois intérpretes analisados, sendo que um deles é o próprio autor, utilizam da fala para narrar a história. Ramón Ayala usa a voz falada no meio da canção ${ }^{5}$, enquanto que o segundo intérprete, Blas Martinez Riera, usa a fala antes de começar a cantar ${ }^{6}$. O fato de que os dois intérpretes da mesma canção usam a voz falada para narrar uma história, num primeiro momento nos leva a pensar no que foi dito por Machado (2012, p.47), de que "essa fala, de alguma maneira, já está inscrita na canção de modo mais ou menos perceptível, e o intérprete apenas atenua o elemento musical para fazer falar a voz que canta", porém, devemos nos atentar que as narrações feitas por eles não tem em si a mesma letra e, encontramse em momentos distintos da interpretação da canção.

Sendo Ramón Ayala, o autor da canção Posadeña Linda, é importante salientar que, durante sua interpretação, de fato, sua fala já está inscrita na letra da canção, como sugere Machado (2012), enquanto que a fala de Blas Martinez Riera é outra, que não está inscrita na letra original da canção.

Outro resultado observado, foi que grande parte dos intérpretes apresentaram tensão na voz Tal recurso, possivelmente, teria sido usado para dar ênfase nas frases mais dramáticas da canção. Segundo Machado (2012, p.46), "a condução da

\footnotetext{
${ }^{5}$ Site < https://www.youtube.com/watch?v=jtEHWvS1ZYl> Acesso: 20 de maio de 2019.

${ }^{6}$ Blas Martinez Riera interpreta "Posadeña Linda" no álbum "El Sabalaje" / faixa 01, lado "B". Site <http://www.fundacionmemoriadelchamame.com/discoteca/82/> Acesso: 20 de maio de 2019.
} 


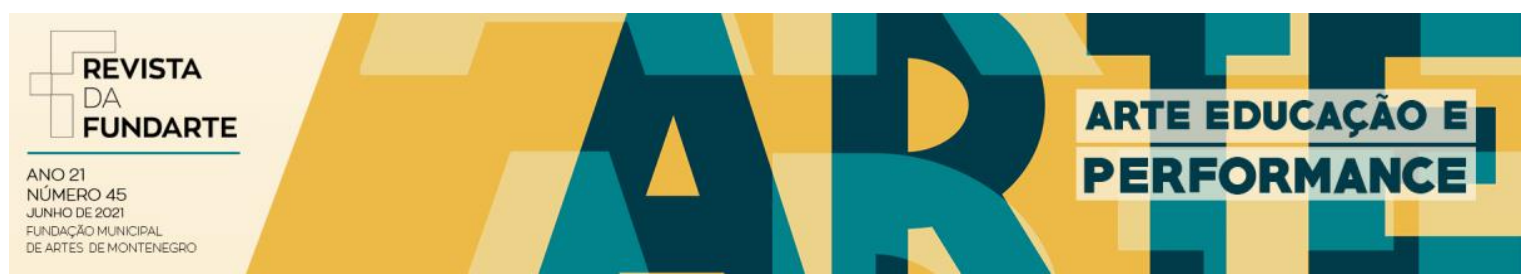

voz em sub-registro de peito a regiões agudas, confere uma percepção de tensionamento físico que muitas vezes reforça, na própria percepção do ouvinte, o componente dramático da interpretação". Para Tatit (2012, p.13), "as tensões melódicas fazem do artista um ser grandioso que se imortaliza no timbre”. O uso da voz em sub-registro de peito foi observado em todos os intérpretes de chamamé analisados neste estudo.

Dois outros recursos muito utilizados por esses intérpretes foram o vibrato e 0 portamento, o primeiro geralmente nas terminações das frases e o segundo, em sua maioria, no início das frases. Também foi possível perceber que a maioria dos intérpretes optou por uma articulação precisa do texto, e com uma ressonância equilibrada, distribuída entre laríngea, oral e nasal. Além disso, todos apresentaram uma voz com bastante brilho.

No que diz respeito a análise dos elementos musicais, os resultados comprovaram o que já havia sido apresentado por Higa (2010).

Por fim, os resultados desta pesquisa nos mostram que no canto do chamamé, há uma necessidade de aproximação entre o ouvinte e a narrativa, de modo que este sinta que é o protagonista da trama cantada. Para isso, os cantores devem, em primeiro plano, utilizar o timbre e a articulação do texto mais próximos aos da fala.

\section{CONSIDERAÇÕES FINAIS}

Se analisarmos pelo ponto de vista da indústria fonográfica, sem nos esquecer, é claro, que a comercialização da música popular urbana, favoreceu, e favorece, a fixação de gêneros e de comportamentos vocais específicos, ligados à interpretação desses gêneros, podemos encontrar um meio de compreender o motivo pelo qual os cantores populares buscam, em suas interpretações, essa proximidade com a fala. Segundo Tatit (2012, p.14), "sem a voz que fala por trás da voz que canta, não há atração nem consumo", isso porque "o público quer saber quem é o dono da voz". Isto foi percebido pelos cantores de chamamé entre as décadas de 1940 e 1980, e deve ser levado em consideração pelos atuais 


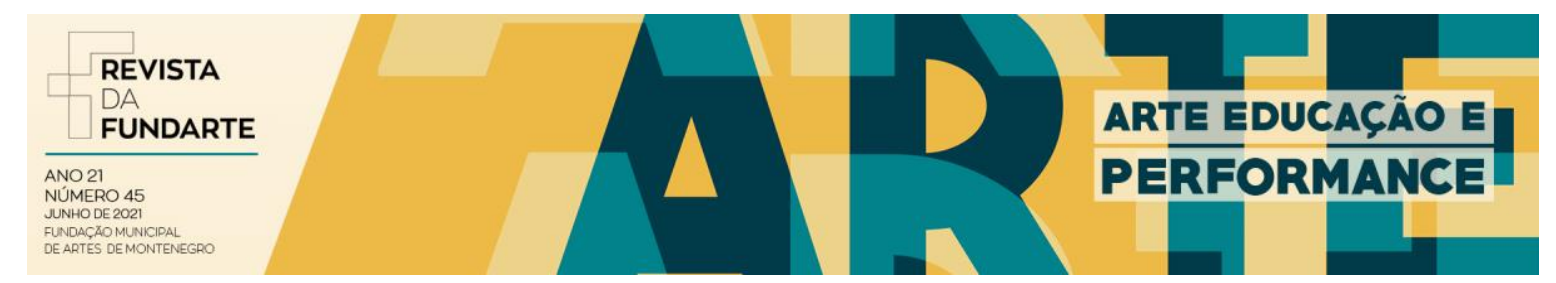

intérpretes desse gênero. Cantores e professores de canto popular devem lançar mão dos recursos mais comuns utilizados na interpretação do chamamé, tais como vibratos, portamentos, articulação próxima à da fala, o uso de voz de peito e todos os efeitos interpretativos que dão ênfase ao texto das canções, se quiserem aproximar-se do ouvinte que aprecia e reconhece a sonoridade tradicional e a identidade vocal deste gênero.

É de grande importância para a cultura latino-americana, que sigamos pesquisando sobre seus gêneros musicais, especialmente sobre a interpretação vocal das canções de cada gênero, a fim de que possamos ajudar a preservar a nossa tradição vocal e cultural e auxiliar os novos intérpretes e as futuras gerações, para que possam ouvir as canções e compreender como eram interpretadas e qual sentido traziam à vida cotidiana dos ouvintes das décadas passadas.

Este estudo nos mostra, além da importância de se continuar pesquisando acerca do canto popular, a importância e a necessidade de se criar materiais didáticos, com exercícios específicos para os gêneros de canções latinoamericanas, a fim de ajudar a preservar algumas das características deste cantar. Segundo Santiago e Nunes (2018, p.1-2), quando o cantor popular, que inicialmente havia aprendido a cantar de maneira intuitiva, "decidia buscar auxílio para aperfeiçoamento na escola, deparava-se com técnicas voltadas ao Canto Erudito, que muitas vezes interferiam nas características estéticas do Canto Popular".

Por fim, anseio que este estudo possa contribuir, significativamente, com as pesquisas acerca da interpretação vocal da canção latino-americana e, especialmente, que venha a ser um material de apoio aos cantores e professores de canto popular, trazendo informações pontuais sobre os aspectos vocais e interpretativos do gênero chamamé. 


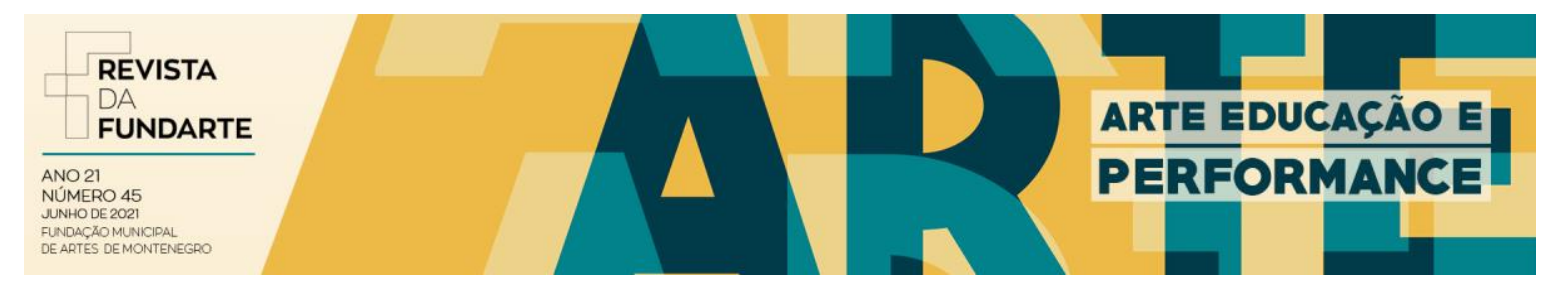

Referências:

CERRUTI, Raul Oscar. El Chamame-Danza Del Folklore Guaranítico Argentino. II Simpósio de Música y Danzas Folklóricas y Tradicionales Argentinas. Casquin (Córdoba). Janeiro, 1964. Argentina: Editorial norte Argentino Resistencia (Chaco), 1965.

CHERNAVSKY, Analía. A performance vocal na canção urbana latino-americana: proposta de estudo a partir das experiências do tango, samba e guarânia. In: XXV Congresso da Associação Nacional de Pesquisa e Pós-Graduação (ANPPOM) Vitória. 2015.

HIGA, Evandro Rodrigues. Polca Paraguaia, Guarânia e Chamamé: estudos sobre três gêneros musicais em Campo Grande-MS. Campo Grande: Editora UFMS, 2010.

MACHADO, Regina. Da intenção ao gesto interpretativo: análise semiótica do canto popular brasileiro. Tese de Doutorado, Universidade de São Paulo. São Paulo, 2012.

PICCOLO, Adriana Noronha. O canto popular brasileiro e a sistematização de seu ensino. In: ANPPOM, Décimo Quinto Congresso. 2005. p. 408-414.

PICCOLO, Adriana Noronha. O canto popular brasileiro: uma análise acústica e interpretativa. Diss. phil.(Mestrado em Música)-Universidade Federal do Rio de Janeiro, 2006.

SANTIAGO, Rute Lopes; NUNES, Thais dos Guimarães Alvim. Processo de construção interpretativa no Canto Popular. In: XI ENCONTRO REGIONAL SUDESTE DA ABEM. 2018.

TATIT, Luiz. O Cancionista: composições de canções no Brasil. Ed. da Universidade de São Paulo, $2^{\text {a }}$ ed. 1ª reimp. São Paulo, 2012. 